\title{
Agricultural Competitiveness of Vietnam by the RCA and the NRCA Indices, and Consistency of Competitiveness Indices
}

\author{
Viet Van Hoang, Khai Tien Tran, Binh Van Tu, Vinh Ngoc Nguyen, An Quynh Nguyen \\ University of Economics Ho Chi Minh City, Vietnam
}

\begin{abstract}
This study measures the static and dynamic agricultural competitiveness of Vietnam by the $R C A$ and the NRCA. The dynamics of the trade competitiveness indicators are assessed in three ways: OLS regression, Markov matrices, and trend analysis. The paper, moreover, tests the consistency between the $R C A$, $N R C A$, and $R T A$ indices. The results show that (i) Vietnam, generally, achieves strong competitiveness in crop and fishery sectors whilst it has weak competitiveness in livestock and processed food sectors; (ii) the country has the convergent pattern of agricultural competitiveness with the high stability of strong competitive and uncompetitive sectors; (iii) the country's agricultural export strategy and competitiveness pattern are based on the natural-resource-intensive and traditional agricultural products with a slight improvement over time; and (iv) the $R C A, N R C A$, and $R T A$ indices are strongly consistent in identifying the degrees of competitiveness and determining whether a country obtains competitiveness while they are weakly consistent in ranking competitiveness.
\end{abstract}

\section{Keywords}

Vietnam, Agriculture, Competitiveness, $R C A$, $N R C A$, Dynamics, Consistency.

Hoang, V. V., Tran, K. T., Tu, B. V., Nguyen, V. N. and Nguyen, A. Q. (2017) "Agricultural Competitiveness of Vietnam by the RCA and the NRCA Indices, and Consistency of Competitiveness Indices", AGRIS on-line Papers in Economics and Informatics, Vol. 9, No. 4, pp. 53-67. ISSN 1804-1930. DOI 10.7160/aol.2017.090406.

\section{Introduction}

International trade competitiveness is the key theme in the economic literature and the crucial issue in the agricultural market and economy of Vietnam. The concept has been, especially, becoming more interesting and essential topic for managers, politicians, and scholars due to the strong process of regionalization and globalization recently. Despite its high popularity of usage and research, the international competitiveness is viewed as the most misunderstood concept in economic theory (Krugman, 1994) and the most arguing definition of what determinants, perspectives, and components are, especially at macro-levels (Martin, 2003). The conventional economics suggests that a country should take advantages of its scarce resources and specialize in producing agricultural sectors with stronger competitive advantages to produce higher values added and create better social welfare as a result. However, a country's economic development and social welfare growth can be decreased by an incorrect specialization (Lucas, 1988; Young, 1991).
In recent decades, the theoretical and empirical international trade studies have paid attention to investigating both the static and dynamic trade performances as a result of the unstable and changing economies and politics, the strong technology development, and the global economic linkages. The recent literature on economic growth and trade also explain that the international trade flow and trade specialization are dynamic and develop endogenously over time (Brasili et al., 2000). The dynamics of trade performances might commonly reflect deep structural changes in the entire economy of a country, as the resources and competitive advantages cannot change quickly despite sudden shocks, new technology, and institutional systems (Ferto and Soos, 2008).

There are several frameworks to measure the competitiveness based on five disciplines such as trade performance indices, economic indicators, determinants of competitiveness, multidimensional frameworks, and value chain performance approaches. The trade performance indices themselves, moreover, include various 
indices such as the NEI, the RCA, the RTA, the $G L I$, the $L F I$, and the $N R C A$ (Hoang et al., 2017). These indices consist of different components with different aggregations based on the revealed trade data. Though the indices may indicate different economic implications such as comparative advantage, specialization, intra-industry trade, and export competitiveness and generate different results they all present the international trade performances. Therefore, it is significant to analyze the consistency among the comparative advantage indices.

Vietnam's transiting economy has moved from centrally planned economy to marketoriented economy since the early 1990s with significant events such as becoming the member of the ASEAN and the WTO, signing the FTAs with Japan, Chile, Korea, EEU, and EU. The country has gone through a stark and important transformation with various economic, global trade, and foreign capital outcomes. The agriculture is, moreover, a key contribution to Vietnam's economy with 17.7 percent of the GDP, 17 percent of the total export, and 48 percent of total employment in 2014 (Hoang et al., 2017). It is, therefore, meaningful to comprehend both the static and dynamic agricultural competitiveness of Vietnam.

This study has the research objectives to (i) measure the static agricultural comparative advantages of Vietnam by using the $R C A$ and the NRCA indices; (ii) assess the dynamics of the trade competitiveness indicators over time by three ways: OLS method, Markov matrix, and trend analysis; and (iii) test the consistency among these trade performance indices. The rest of the paper consists of the literature review on international trade theory and these trade performance indices; the next section describes the methods and materials used for this article; the result and discussion part will present and explain the empirical results; and the final section will conclude the research findings.

\section{Literature review}

The traditional economic theory defines the competitiveness based on the concepts of the absolute advantage of Smith and the comparative advantage of Ricardo and measures the concept by the basic production indicators such as productivity, price, and cost. Due to the unavailability of productivity, price, and cost data, scholars have developed measuring models for the empirical studies based on the revealed trade data. Balassa (1965) builds the revealed comparative advantage $(R C A)$ index based on the traditional trade theory and the first empirical utilization of Liesner(1958). The $R C A$ uses the export flows to compute the ratio of a country's export share of one commodity in the international market to the country's export share of all other commodities. Balassa explains that comparative advantage is revealed in relatively high shares of export markets and comparative disadvantage is revealed in relatively low shares of export markets. The shares have to be compared with others to evaluate which country or commodity is comparative advantage and disadvantage (Gorton et al., 2000). Economics scientists identify the main restrictions of the $R C A$ such as: (i) the index serves as export specialization measure; (ii) the $R C A$ is static and does not present the dynamics of comparative advantage over time; (iii) it does not include import data; (iv) the distribution of the $R C A$ indicators is the asymmetric and non-normal; (v) its range from 0 to $+\infty$ has problematic matters to interpret and compare; (vi) it double counts the data of a country and a commodity; (vii) the index shows the success in exporting to the world market. The exports, however, can come from incentives and the incentives can explain competitiveness, not comparative advantage (Vollrath, 1991; Kreinin and Plummer, 1994; Dalum et al., 1998; Proudman and Redding, 2000; Hoen and Oosterhaven, 2006; Hoang et al., 2017).

Despite the criticisms and concerns over the tradedistorting effects of government interference and inability to identify the sources of comparative advantage, scholars and the authors maintain the thinking that the $R C A$ index, when employed judiciously, still gives useful evidence of the comparative advantages in agricultural sectors. The $R C A$ is also one of the most cited and employed indices to investigate comparative advantage in several empirical studies such as Esquivias (2017), Nath et al. (2015), Kuldilok et al. (2013), and Abidin and Loke (2008).

Alternative measures have been proposed to deal with the limitations of the $R C A$. Vollrath (1991) suggests the relative trade advantage (RTA) that is calculated as the difference between the relative export advantage, similar to the RCA index, and the relative import advantage. Dalum et al. (1998) construct the transformation of the $R C A$ that is calculated by $(R C A-1) /(R C A+1)$ and called as the revealed symmetric comparative advantage 
index (RSCA). Proudman and Redding (2000) propose arithmetic mean of the country's $R C A$ (WRCA) to weigh a country's $R C A$ index for a particular product and establish the comparability within an individual country. Hoen and Oosterhaven (2006) explain that the limitations of the $R C A$ are created by its multiplicative form and they propose an additive $R C A \quad(A R C A)$ index in order to make the distribution of the original index stable with respect to countries. The sum of a country's $A R C A$ scores is constant and equals to zero, which makes the comparison of a country's comparative advantage in different commodities practicable. The ARCA index, however, does not create comparability across country as the sum of all countries' $A R C A$ scores for an individual commodity is not a constant and the index is also sensitive to the size of a sector (Yu et al., 2009). Cai and Leung (2008) suggest the $R C A$ variation $(R C A V)$ index to provide a more general measure of the variation in comparative advantage than the simple comparison of the $R C A$ over time.

According to Yu et al. (2009), these alternative $R C A$ indices might improve the $R C A$ index in certain aspects, but none of them successfully overcome all the shortcomings. These scholars, therefore, propose the normalized revealed comparative advantage (NRCA) index as an alternative and improved measure of the $R C A$ index based on the probabilistic approach of Kunimoto (1977). The NRCA index is expressed as the normalized form of the level deviations in actual trade flows from their expected levels.

The NRCA, in general, has four properties eliminating the drawbacks of Balassa's index. First, it is symmetrical as its value ranges from -0.25 to 0.25 with 0 being the comparativeadvantage-neutral point. Second, the sum and the mean value of a country or a commodity's $N R C A$ scores are constant and equal to zero. This reflects the relative nature of comparative advantage as when a country obtains comparative advantage in a commodity, some other countries must lose comparative advantage in this commodity, and when a country obtains comparative advantage in some commodities, it must lose comparative advantage in some other commodities. Third, it is independent of the classification of the commodities and countries. In other words, the aggregation levels of data have no influence on the NRCA and the index is additive over country and commodity. Hence, the NRCA index is comparable across country, across commodity, and over time. Fourth, the NRCA captures the situation of zero export in a more reasonable way as NRCA score for zero export is not invariant. If two countries have zero export of a commodity, the "large" country would have more comparative disadvantage in this commodity than the "small" country; likewise, if a country has zero export in two commodities, the country would have more comparative disadvantage in the "large" commodity than in the "small" commodity (Yu et al., 2009). The NRCA has been employed in empirical studies to measure the cross-sector and cross-country comparative advantages over time and to compare with other trade performance indices such as Deb and Hauk (2017), Ceglowski (2017), Seleka and Kebakile (2017), Sarker and Ratnasena (2014).

\section{Materials and methods}

Balassa (1965) builds the revealed comparative advantage $(R C A)$ index based on the first analysis of comparative advantage by Liesner (1958). The idea of the index is to compare the performance of a country in a commodity with the performance of a reference group of countries by using the observed export patterns or the revealed data. The RCA index can be defined as follows:

$R C A_{i j}=\left[\frac{X_{i j}}{X_{i}}\right] \div\left[\frac{X_{w j}}{X_{w}}\right]$

where, $X_{i j}$ represents country i's export of product $j$, $X_{i}$ is the total export of country $i . X_{w i}$ is the world's export of commodity $j$, and $X_{w}$ is the total export of the world. The value of $R C A$ ranges between 0 and $+\infty$, and the comparative-advantage-neutral point is 1 . If the $R C A$ value $>1$, the country has the comparative advantage in the product. If the $R C A$ value $<1$, the country has the comparative disadvantage in the product. The index reveals a higher comparative advantage, namely an index number of 1.1 will mean that the country's share in this commodity's exports is $10 \%$ higher than its share of the total exports. The $R C A$ can be interpreted in three ways: dichotomous, ordinal and cardinal (Ferto and Hubbard, 2003). First, the $R C A$ is employed to assess the existence of comparative advantage in a product, the second way is useful for ranking countries or sectors, and the third interpretation is to measure the dimension of the $R C A$. This study follows the quartile method in Hinloopen and Marrewijk (2001) to identify the degree of comparative advantage and group the $R C A$ 
indicators into four classes such as comparative disadvantage, weak comparative advantage, medium comparative advantage, and strong comparative advantage.

$\mathrm{Yu}$ et al. (2009) construct the NRCA index as a deviation between the expected and actual export of a country. According to these scholars, the idea of the normalized revealed comparative advantage index is to measure the degree of deviation of a specific country's actual export from its comparative-advantage-neutral level in terms of its relative scale with respect to the world export market and thus establishes its comparability across commodity and country. The country's export of commodity $j$ at the comparative-advantage-neutral point, $\hat{X}_{i j}$, is derived from the comparative-advantage-neutral point of the RCA index:

$R C A_{i j}=\frac{\hat{X}_{i j}}{X_{i}}: \frac{X_{w j}}{X_{w}}=1$

the $\hat{X}_{i j}$, thus, is characterized by $X_{i} X_{w j} / X_{w}$. The deviation of the actual export, $X_{i j}$, and expected one, $\hat{X}_{i j}$, can be stated as:

$$
\Delta X_{i j}=X_{i j}-\widehat{X}_{i j}=X_{i j}-\frac{X_{i} X_{w j}}{X_{w}}
$$

after normalizing $\Delta X_{i j}$ by the world total export, $X_{w}$, the NRCA index is obtained as follows:

$$
N R C A_{i j}=\frac{\Delta X_{i j}}{X_{w}}=\frac{X_{i j}}{X_{w}}-\frac{X_{i} X_{w j}}{X_{w} X_{w}}
$$

The NRCA index ranges from -0.25 to 0.25 , the comparative-advantage-neutral point is zero when the actual export is identical to the expected export of the country. The economic interpretations of the $N R C A$ index are as follows: the $N R C A>0$ presents the country i's actual export of commodity $j$ is higher than its expected export of commodity $j$, the comparative-advantage-neutral level, thus the country has comparative advantage in the commodity. The $N R C A<0$ indicates that the country i's actual export of commodity $j$ is lower than its expected export of the commodity, thus the country has comparative disadvantage in the commodity. The higher the NRCA values is, the stronger the comparative advantage would be, and vice versa. Following Yu et al. (2009), this study rescales the $N R C A$ values to facilitate the presentation of the results by multiplying a constant 10,000 without affecting on the result.

According to Hinloopen and Marrewijk (2001) and Hoang et al. (2017), there are at least three types of dynamics of comparative advantage (CA) indicators: (i) the stability of the distribution of the trade performance indices from one period to the next; (ii) the mobility and stability of the competitiveness values for every year of the period; and (iii) the trends of the $C A$ values over the period and in the future. Following Dalum et al. (1998), the first type of the competitiveness dynamics is analyzed by using OLS method presented by Hart \& Prais (1956) and first utilized by Cantwell (1989) in the context of specialization. The OLS regression of competitive advantage dynamics may be presented as follows:

$$
C A_{i j}^{t 2}=\alpha_{i}+\beta_{i} C A_{i j}^{t 1}+\varepsilon_{i j}
$$

where, the $C A$ represents the agricultural comparative advantage indices, $t_{1}$ and $t_{2}$ are the initial years and the final years, $j$ is the agricultural sector under study, $\alpha$ is a constant, $\beta$ is a regression coefficient, and $\varepsilon_{j}$ is a residual term. The $C A$ value at time $t_{2}$ for the agricultural sector $j$ is the dependent variable and tested against the independent variable of the $C A$ value at time $t_{1}$ for the agricultural sector $j$. Dalum et al. (1998) affirm that the method is useful for comparing crosssections or cross-countries at two points in time and there is no factor of time in the observations. In this study, it is assumed that regression is linear in parameters and the residual $\varepsilon_{i j}$ is normal identically distributed $\left(\varepsilon_{i j} \sim\right.$ n.i.d. $\left.(0, \sigma)\right)$.

The interpretation of the regression results is as follows. The $\beta=1$ corresponds to the unchanged pattern of the competitiveness from $t_{1}$ to $t_{2}$. If $\beta>1$, the country obtains comparative advantage in sectors with initial strong competitiveness and losses comparative advantage in sectors with initial weak competitiveness. On the other hand, if $0<\beta<1$, sectors with initial weak competitiveness gain comparative advantage, whilst sectors with initial strong competitiveness lose comparative advantage. If $\beta=0$, there is no relation between the $C A$ indicators in two periods. If $\beta<0$, the competitiveness positions of the agricultural sectors are reversed. In other words, those $C A$ indicators initially below the average value will be above the average finally, and vice versa.

According to Dalum et al. (1998) and Cantwell (1989), another feature of the regression analysis is to test whether the degree of competitiveness changes over time and $\beta>1$ is not a necessary condition for growth in the overall specialization 
pattern. It can be shown that (Hart, 1976):

$\frac{\sigma_{i}^{t 2}}{\sigma_{i}^{t 1}}=\frac{\left|\beta_{i}\right|}{\left|R_{i}\right|}$

where, $R$ is the correlation coefficient from the regression model and $\sigma$ is the standard deviation of the dependent variable. The dispersion of a given distribution is unchanged when $\beta=R$. If $\beta>R$ (equivalent to the increase in the dispersion), then the degree of the specialization rises. If $\beta<R$ (equivalent to the decrease in the dispersion), then the degree of specialization falls.

The asymmetric problem, however, violates the assumption of normality of the error term in the regression analysis, which makes the t-statistics unreliable. The values of the $N R C A$ indicators are in $(-0.25,0,+0.25)$, thus it eliminates the asymmetric problem. However, the values of the $R C A$ indicators are in $(0,+\infty)$, the distribution thus violates the assumption of normality of the error term in the regression analysis. Additionally, using the $R C A$ indicator in regression analysis gives much more weight to values above one, as compared to observations below one. To deal with the asymmetric problem, Dalum et al. (1998) transform the $R C A$ index into the revealed symmetric comparative advantage index ( $R S C A)$ with the same economic implications as follows:

$R S C A=\frac{R C A-1}{R C A+1}$

The $R S C A$ value ranges from -1 to +1 . The $R S C A$ index translates the values from the intervals of $R C A$ index $(0,1] ;[1,+\infty)$ into $(-1,0] ;[0,+1)$. The main advantage of this index is that it makes below the unity the same weight as changes above the unity.

The second type of stability of the $C A$ values is assessed in two ways. First, following the empirical method utilized first by Proudman and Redding (2000), this paper employs one-step Markov chains to analyze the probability of transition among four classes categorized by quartile method in term of its moving from an initial class to other classes in onestep of moving (moving within two adjacent years) and the persistence of stability in the initial class. Secondly, the mobility degree of the $C A$ values is analyzed by the mobility index. The index identifies the degree of mobility throughout the entire distribution of the $C A$ values and facilitates direct cross-sections comparisons over the full period. The $M$ index, following Shorrocks (1978), assesses the trace of the transition probability matrix. This $M$ index, thus, directly captures the relative and medium magnitude of diagonal and off-diagonal terms, and the equation of $M$ index can be shown as follows:

$M=\frac{n-\operatorname{tr}(P)}{n-1}$

where, $M$ is Shorrocks index, $\mathrm{n}$ is the number of classes, $P$ is the transition probability matrix, and $\operatorname{tr}(P)$ is the trace of $P$. The higher values of $M$ index indicate greater mobility while the lower values of $\mathrm{M}$ index show lower mobility of the $C A$ value among the classes of comparative advantages. The zero value of $M$ index means the perfect immobility.

The research, finally, employs the trend analysis to examine and predict the $C A$ trend of a particular agricultural sector over the period and in the future. This tool identifies the $C A$ gaining, losing, or maintaining trends in an agricultural sector based on comparing the changes of the $C A$ values over time. The time trend model can be presented as follows:

$$
C A_{i j}^{t}=\alpha_{i j}+\beta_{i j} t+\varepsilon_{i j}^{t}
$$

where, $\alpha_{i j}$ is a constant; $\beta_{i j}$ is the regression coefficient showing the $C A$ trend; $t$ is the time index; and $\varepsilon_{i j}^{t}$ is a residual term. Vietnam's $C A$ in agricultural sector $j$ can be considered stable if the estimated $\beta_{i j}$ is close to zero (with the significance level of 10 percent). The value of $\beta_{i j}>0$ indicates a trend in gaining the competitive advantage while the value of $\beta_{i j}<0$ means a trend in losing the competitive advantage.

The data for this study is obtained from the United Nations Comtrade based on Revision 3 of the Standard International Trade (SITC Rev. 3). The paper follows the definitions of the WTO and the EU for the "agricultural commodities" to cover the codes of "section 0,1 , division 21, 22, group 231, division 24, group 261, 263, 264, 265, 268, division 29, and section 4" in the SITC Rev. 3. This paper calculates the comparative advantages at 3-digit with 61 agricultural commodity groups over the period $1997-2014$. The study considers the concept "agricultural commodity group" as the "agricultural sector" to ease and clear the writing and interpretations. The authors use the code of commodity for the writing and interpretations with the full commodity description in Table 1. 


\section{Result and discussion}

\section{Measuring the comparative advantage by the $R C A$ and the $N R C A$}

Table 1 presents the agricultural comparative advantages of Vietnam by the $R C A$ and the NRCA. The results show that, in 2014, Vietnam obtains the strongest $R C A$ in 246 with the $R C A$ value of 18.41 whilst it obtains the strongest $N R C A$ in 071 with the $N R C A$ value of 1.76 . The next top strong $R C A$ sectors are $075,042,231,071,036$, and 037 with the $R C A$ values of $17.57,14.00$, $12.52,11.31,9.54$, and 8.92 , respectively whilst those by the NRCA are 042,036,034, 037, 057, and 231 with the $N R C A$ values of $1.48,1.45,1.18$, $0.96,0.94$, and 0.83 , respectively. There is a relative difference in the top competitiveness positions of the agricultural sectors between the $R C A$ and the NRCA. These indices also differently indicate the weakest comparative advantage sectors. The country has the weakest $R C A$ in 244 , $212,043,268$, and 023 while it has the weakest $N R C A$ in 222, 012, 112, 041, and 011. Though the top competitiveness positions are different between the RCA and the NRCA, these sectors still stay in the top strong competitiveness groups. The positions of the next strong competitiveness sectors are different between the indices.

The degree of agricultural competitiveness will be measured by the classification of the $R C A$ and $N R C A$ values into four classes by quartile method (Table 4). By the $R C A$, Vietnam has four strong competitive agricultural sectors, four medium competitive agricultural sectors, and 11 weak competitive agricultural sectors. Vietnam achieves the competitiveness in 19 agricultural sectors in 2014, while it has the competitiveness in 22 sectors in 1997 and 23 sectors in the average of the period. There are relative variations between the $R C A$ values in 2014 and in 1997. This indicates the change of the $R C A$ values over time. By the NRCA, Vietnam has nine strong competitive sectors, two medium competitive sectors, and eight weak competitive sectors in 2014. Vietnam also gains the comparative advantage in 19 agricultural sectors in 2014, while it has the competitiveness in 22 sectors in 1997 and 22 sectors in the average of the period. The difference between the NRCA values in 2014 and in 1997 indicates the change of the NRCA values over time. There are, generally, variations between the $R C A$ and the NRCA in positioning the competitiveness rankings of the agricultural sectors while they are identical to determine whether an agricultural sector is competitive. This is proved by the similar numbers of competitive sectors by the $R C A$ index and the $N R C A$ index both in 1997 (with 22 sectors) and in 2014 (with 19 sectors).

In overall, by both the $R C A$ and the $N R C A$, Vietnam achieves strong comparative advantages in the crop sectors such as spices, rice, coffee, tea, fruit and nut, and vegetables; and the fishery sectors such as crustaceans and fish whilst the country has weak comparative advantages in the livestock sectors such as live animal, meat, and eggs and birds; and the processed food sectors such as chocolate, cheese, butter, and other processed meat and foods. In other words, the country has agricultural export strategy and comparative advantage based on the natural-resource-intensive and traditional agricultural products. The naturalresource-intensive export strategy is important in the initial period of economic development and globalization. However, the strategy is not appropriate and effective to develop the country's economy in the medium and long terms. The dynamics of comparative advantage will be analyzed for more understanding how Vietnam's export strategy and comparative advantage pattern evolve along with its economic growth and globalization process.

Analyzing the dynamics of the agricultural comparative advantage indicators

\section{The general pattern of the $R S C A \quad(R C A)$ and $N R C A$ indicators by OLS method}

The estimation results for the RSCA indicators result in the values of $0<\beta<1$ and values of $\beta / R<1$ over three periods (Table 2) (the RSCA is in replace for the $R C A$ for regression without changing economic implications). The results indicate that Vietnam, in general, has the convergent pattern in the agricultural competitiveness. In other words, the country loses the competitiveness in the initial strong competitive agricultural sectors whilst it gains the competitiveness in the initial weak competitive agricultural sectors. The values of $0<\beta<1$ also show the process of de-specialization in Vietnam's agricultural export competitiveness. The possible explanation for the result is that Vietnam's agricultural competitiveness pattern is based on natural resources with the primary agricultural products, thus the country's increases in the productions and exports of the strong competitive sectors will result in the utilization of higher opportunity cost resources. Therefore, the competitive advantages of these sectors decrease. On the other hand, 
the resources of the new and weak competitive advantage sectors are still abundant with lower opportunity cost resources. Therefore, the competitive advantages of these sectors increase. This result is consistent with the traditional economic theory explaining that a country tends to decrease the competitive advantage in a product when it increases the specialization and exports the product to the world market.

The estimation results for the $N R C A$ indicators bring in the values of $\beta>1$ and the values $\beta / R>1$ over three periods (Table 3 ). The results confirm that Vietnam has a divergent pattern in agricultural competitiveness or the country increases in the overall specialization trade pattern. In other words, Vietnam gains the increasing competitiveness in the initial strong competitive sectors whilst it loses the competitiveness in the initial weak competitive sectors. This result of the NRCA, however, seems to be contrary to those of the RSCA indicators.

\section{The mobility and stability of the competitiveness indicators by Markov matrix}

The $R C A$ and the $N R C A$ values are classified into four groups including the comparative disadvantage, weak comparative advantages, medium comparative advantages, and strong comparative advantages. The boundary of competitive and uncompetitive groups is remained and the $R C A$ and the $N R C A$ values are then divided into 3 classes of weak, medium

\begin{tabular}{|c|c|c|c|c|c|c|}
\hline No. & Code & Commodity & RCA(1997) & RCA (2014) & NRCA (1997) & NRCA (2014) \\
\hline 1 & 001 & Live animals & 0.11 & 0.03 & -0.03 & -0.10 \\
\hline 2 & 011 & Bovine meat & 0.00 & 0.00 & -0.04 & -0.21 \\
\hline 3 & 012 & Other meat, meat offal & 0.66 & 0.10 & -0.03 & -0.31 \\
\hline 4 & 016 & Meat,ed.offl,dry,slt,smk & 0.09 & 0.01 & -0.01 & -0.02 \\
\hline 5 & 017 & Meat,offl.prpd,prsvd,nes & 0.54 & 0.04 & -0.01 & -0.09 \\
\hline 6 & 022 & Milk and cream & 0.02 & 0.23 & -0.04 & -0.17 \\
\hline 7 & 023 & Butter,other fat of milk & 0.00 & 0.00 & -0.01 & -0.04 \\
\hline 8 & 024 & Cheese and curd & 0.00 & 0.00 & -0.03 & -0.15 \\
\hline 9 & 025 & Eggs,birds,yolks,albumin & 4.06 & 0.14 & 0.02 & -0.02 \\
\hline 10 & 034 & Fish,fresh,chilled,frozn & 2.74 & 5.22 & 0.11 & 1.18 \\
\hline 11 & 035 & Fish,dried,salted,smoked & 4.10 & 1.48 & 0.03 & 0.01 \\
\hline 12 & 036 & Crustaceans,molluscs etc & 20.62 & 9.54 & 0.98 & 1.45 \\
\hline 13 & 037 & Fish etc.prepd,prsvd.nes & 6.76 & 8.92 & 0.18 & 0.96 \\
\hline 14 & 041 & Wheat, meslin, unmilled & 0.01 & 0.00 & -0.06 & -0.21 \\
\hline 15 & 042 & Rice & 66.33 & 14.00 & 1.61 & 1.48 \\
\hline 16 & 043 & Barley, unmilled & 0.00 & 0.00 & -0.01 & -0.03 \\
\hline 17 & 044 & Maize unmilled & 0.51 & 0.12 & -0.02 & -0.13 \\
\hline 18 & 045 & Other cereals, unmilled & 0.12 & 0.02 & 0.00 & -0.02 \\
\hline 19 & 046 & Meal,flour of wheat,msln & 0.16 & 1.49 & -0.01 & 0.01 \\
\hline 20 & 047 & Other cereal meal,flours & 0.07 & 0.24 & 0.00 & -0.01 \\
\hline 21 & 048 & Cereal preparations & 0.32 & 0.45 & -0.03 & -0.13 \\
\hline 22 & 054 & Vegetables & 1.34 & 1.95 & 0.02 & 0.26 \\
\hline 23 & 056 & Vegtables,prpd,prsvd,nes & 0.94 & 0.57 & 0.00 & -0.06 \\
\hline 24 & 057 & Fruit,nuts excl.oil nuts & 2.50 & 3.22 & 0.14 & 0.94 \\
\hline 25 & 058 & Fruit,preserved,prepared & 5.64 & 1.03 & 0.09 & 0.00 \\
\hline 26 & 059 & Fruit, vegetable juices & 0.06 & 0.30 & -0.02 & -0.05 \\
\hline 27 & 061 & Sugars,molasses, honey & 0.21 & 0.89 & -0.03 & -0.02 \\
\hline 28 & 062 & Sugar confectionery & 0.55 & 1.02 & -0.01 & 0.00 \\
\hline 29 & 071 & Coffee,coffee substitute & 17.45 & 11.31 & 0.88 & 1.76 \\
\hline 30 & 072 & Cocoa & 0.00 & 0.04 & -0.02 & -0.08 \\
\hline 31 & 073 & Chocolate,oth.cocoa prep & 0.01 & 0.04 & -0.02 & -0.12 \\
\hline
\end{tabular}

Source: own calculation based on data of UN Comtrade (2017)

Table 1: Vietnam's agricultural trade competitiveness by the RCA and the NRCA (to be continued). 


\begin{tabular}{|c|c|c|c|c|c|c|}
\hline No. & Code & Commodity & $\operatorname{RCA}(1997)$ & RCA (2014) & NRCA (1997) & NRCA (2014) \\
\hline 32 & 074 & Tea and mate & 11.38 & 3.60 & 0.08 & 0.09 \\
\hline 33 & 075 & Spices & 21.29 & 17.57 & 0.15 & 0.68 \\
\hline 34 & 081 & Animal feed stuff & 0.08 & 0.71 & -0.07 & -0.11 \\
\hline 35 & 091 & Margarine and shortening & 0.05 & 0.01 & -0.01 & -0.03 \\
\hline 36 & 098 & Edible prod.preprtns,nes & 2.70 & 0.66 & 0.10 & -0.12 \\
\hline 37 & 111 & Non-alcohol.beverage,nes & 0.84 & 0.46 & 0.00 & -0.05 \\
\hline 38 & 112 & Alcoholic beverages & 0.21 & 0.27 & -0.07 & -0.26 \\
\hline 39 & 121 & Tobacco, unmanufactured & 0.07 & 0.28 & -0.02 & -0.04 \\
\hline 40 & 122 & Tobacco, manufactured & 0.09 & 0.95 & -0.06 & -0.01 \\
\hline 41 & 211 & Hides,skins(ex.furs),raw & 0.67 & 0.08 & -0.01 & -0.03 \\
\hline 42 & 212 & Furskins, raw & 0.00 & 0.00 & 0.00 & -0.02 \\
\hline 43 & 222 & Oilseed(sft.fix veg.oil) & 2.02 & 0.02 & 0.05 & -0.34 \\
\hline 44 & 223 & Oilseed(oth.fix.veg.oil) & 0.25 & 0.39 & 0.00 & -0.01 \\
\hline 45 & 231 & Natural rubber, etc. & 19.90 & 12.52 & 0.34 & 0.83 \\
\hline 46 & 244 & Cork, natural, raw; waste & 0.00 & 0.00 & 0.00 & 0.00 \\
\hline 47 & 245 & Fuel wood, wood charcoal & 6.53 & 1.31 & 0.01 & 0.00 \\
\hline 48 & 246 & Wood in chips, particles & 4.99 & 18.41 & 0.02 & 0.57 \\
\hline 49 & 247 & Wood rough,rough squared & 0.01 & 0.41 & -0.02 & -0.04 \\
\hline 50 & 248 & Wood, simply worked & 0.19 & 0.79 & -0.07 & -0.04 \\
\hline 51 & 261 & Silk & 6.59 & 0.22 & 0.01 & 0.00 \\
\hline 52 & 263 & Cotton & 0.12 & 0.21 & -0.02 & -0.05 \\
\hline 53 & 264 & Jute,oth.textl.bast fibr & 1.89 & 1.62 & 0.00 & 0.00 \\
\hline 54 & 265 & Vegetable textile fibres & 3.97 & 3.98 & 0.00 & 0.02 \\
\hline 55 & 268 & Wool, other animal hair & 0.38 & 0.00 & -0.01 & -0.03 \\
\hline 56 & 291 & Crude animal materls.nes & 4.28 & 0.27 & 0.04 & -0.03 \\
\hline 57 & 292 & Crude veg.materials, nes & 0.69 & 0.28 & -0.01 & -0.13 \\
\hline 58 & 411 & Animal oils and fats & 0.01 & 1.31 & -0.01 & 0.01 \\
\hline 59 & 421 & Fixed veg.fat,oils, soft & 0.08 & 0.44 & -0.04 & -0.09 \\
\hline 60 & 422 & Fixed veg.fat,oils, other & 1.60 & 0.20 & 0.02 & -0.15 \\
\hline \multirow[t]{4}{*}{61} & 431 & Animal,veg.fats,oils, nes & 0.03 & 0.12 & -0.01 & -0.05 \\
\hline & & Max & 66.33 & 18.41 & 1.61 & 1.76 \\
\hline & & Average & 3.72 & 2.12 & 0.07 & 0.11 \\
\hline & & Competitive sectors & 22 & 19 & 22 & 19 \\
\hline
\end{tabular}

Source: own calculation based on data of UN Comtrade (2017)

Table 1: Vietnam's agricultural trade competitiveness by the RCA and the NRCA (continuation).

\begin{tabular}{|c|c|c|c|c|c|c|c|c|}
\hline \multicolumn{3}{|c|}{$1997-\mathbf{2 0 0 5}$} & \multicolumn{3}{c|}{ 2006-2014 } & \multicolumn{3}{c|}{1997 - 2014 } \\
\hline$\beta$ & $\mathrm{R}$ & $\beta / \mathrm{R}$ & $\beta$ & $\mathrm{R}$ & $\beta / \mathrm{R}$ & $\beta$ & $\mathrm{R}$ & $\beta / \mathrm{R}$ \\
\hline 0.74 & 0.79 & 0.95 & 0.83 & 0.89 & 0.93 & 0.63 & 0.71 & 0.89 \\
\hline
\end{tabular}

Source: own calculation based on data of UN Comtrade (2017)

Table 2: The OLS estimation results for the RSCA indicators over three periods.

\begin{tabular}{|c|c|c|c|c|c|c|c|c|}
\hline \multicolumn{3}{|c|}{$1997-\mathbf{2 0 0 5}$} & \multicolumn{3}{c|}{ 2006-2014 } & \multicolumn{3}{c|}{$1997-2014$} \\
\hline$\beta$ & $\mathrm{R}$ & $\beta / \mathrm{R}$ & $\beta$ & $\mathrm{R}$ & $\beta / \mathrm{R}$ & $\beta$ & $\mathrm{R}$ & $\beta / \mathrm{R}$ \\
\hline 1.05 & 0.91 & 1.15 & 1.36 & 0.92 & 1.48 & 1.34 & 0.81 & 1.67 \\
\hline
\end{tabular}

Source: own calculation based on data of UN Comtrade (2017)

Table 3: The OLS estimation results for the NRCA indicators over three periods. 


\begin{tabular}{|l|l|c|c|}
\hline Categories & Interpretation & RCA Values & NRCA values \\
\hline Class 1 & Comparative disadvantage & $\leq 1$ & $\leq 0$ \\
\hline Class 2 & Weak comparative advantage & $\leq 4.44$ & $\leq 0.067$ \\
\hline Class 3 & Medium comparative advantage & $\leq 12.26$ & $\leq 0.478$ \\
\hline Class 4 & Strong comparative advantage & $>12.26$ & $>0.478$ \\
\hline
\end{tabular}

Source: own calculation based on data of UN Comtrade (2017)

Table 4: The classes of the RCA and the NRCA values and the interpretations.

\begin{tabular}{|l|l|r|r|r|r|}
\hline & Obs: 1,037 & Class 1 & Class 2 & Class 3 & Class 4 \\
\hline M-Shorrocks & Class 1 & 94.89 & 4.82 & 0.15 & 0.15 \\
\hline 0.19 & Class 2 & 20 & 73.14 & 6.86 & 0 \\
\hline Average stability & Class 3 & 3.41 & 15.91 & 78.41 & 2.27 \\
\hline 85.49 & Class 4 & 0 & 0 & 4.49 & 95.51 \\
\hline Average mobility & Total & 66.35 & 16.88 & 8.29 & 8.49 \\
\hline 4.84 & Long run & 70.31 & 16.74 & 7.16 & 5.78 \\
\hline
\end{tabular}

Source: own calculation based on data of UN Comtrade (2017)

Table 5: The M-Shorrocks and Markov transition matrix for the RCA values.

\begin{tabular}{|c|c|c|c|c|c|}
\hline & Obs: $\mathbf{1 , 0 3 7}$ & Class 1 & Class 2 & Class 3 & Class 4 \\
\hline M-Shorrocks & Class 1 & 94.89 & 4.96 & 0.15 & 0 \\
\hline 0.17 & Class 2 & 20.79 & 73.03 & 6.18 & 0 \\
\hline Average stability & Class 3 & 1.1 & 12.09 & 80.22 & 6.59 \\
\hline 87.04 & Class 4 & 0 & 0 & 0 & 100 \\
\hline Average mobility & Total & 66.35 & 16.88 & 8.2 & 8.58 \\
\hline 4.32 & Long run & 64.1 & 3.73 & 3.87 & 28.39 \\
\hline
\end{tabular}

Source: own calculation based on data of UN Comtrade (2017)

Table 6: The M-Shorrocks and Markov transition matrix for the NRCA values.

and strong comparative advantages by quartile method (Table 4). Let $p_{i j}(i, j=1,2,3,4)$ denotes a one-step transition probability, that is the transition probability for the agricultural sectors which are in class " $i$ " of year " $t$ " moving to class " $j$ " of year " $t+1$ ".

The stability and mobility of the $R C A$ indicators are investigated by using the Markov transition probability matrix and mobility index for yearly values of the $R C A$ values from 1997 to 2014 . The diagonal elements of the Markov matrix show the probability of remaining persistently in the initial class. The other elements of the Markov transition probability matrix provide further information on the mobility of the $R C A$ values. Specifically, they show the probabilities of moving from one class to another from the year " $t$ " to the year " $t+1$ ". There is a $4 \times 4$ matrix with 1,037 observations. The result indicates that the high probabilities of the $R C A$ indicators remain in their initial class (high diagonal elements) in which the uncompetitive sectors with 94.89 percent and the strong competitive sectors with 95.51 percent maintain the highest probabilities and they are the most persistent. In other words, the sectors with initial comparative disadvantage seem to stay comparative disadvantage whilst the sectors with initial strong competitiveness maintain to be strongly competitive. The average stability in initial class is 85.49 percent whilst the average mobility to other class is 4.84 percent. There is no sector moving from class 4 backwards class 1 and class 2, and from class 2 forward class 4. The M-Shorrocks of 0.19 , generally, shows a relatively low degree of mobility between the classes in Markov matrix (Table 5).

The result in Table 6 shows high stabilities in the NRCA indicators over time. The sectors in class 1 and class 4 obtain the highest probabilities of stabilities with 94.89 percent and 100 percent. In other words, the initial weakest competitive agricultural sectors steadily continue to stay in their group over time and the strong competitive agricultural sectors perfectly remain in their initial positions. Several sectors move from class 2 
to class 1, class 3 to class 2 while there is no sector moving from class 4 backwards class 1,2 and 3 as well as from class 1, 2 forward class 4 . The average probability of stability or diagonal elements is 87.04 whilst the average value of mobility or off-diagonal elements is only 4.32 percent. The M-Shorrocks index of 0.17 confirms a low degree of mobility of the NRCA indicators. The total and the long run distributions in the $R C A$ 's matrix are relatively similar and this indicates that the Markov matrix accurately captures the underlying distribution of the $R C A$ indicators. Whereas the total and the long run distributions are relatively different in the $N R C A$ 's matrix and that difference indicates that the shares of uncompetitive sectors increase whilst the competitive sectors decline.

\section{The trends of the RCA and the NRCA indicators}

The result of trend analysis for the $R C A$ indicators during the period of 1997-2014 shows that Vietnam has the gaining trends in 19 agricultural sectors with $\beta>0$ and the losing trends in 23 agricultural sectors with $\beta<0$. The sectors of 246, 037, 034265 , and 411 obtain the most growing trend in comparative advantage. This suggests that Vietnam continues to obtain the stronger comparative advantage in these commodities in the future. During the same period, the sectors of $042,036,245,231$, and 071 incur the most decreasing trends in comparative advantage (Table 7).
The trend analysis result of the NRCA values over the period 1997-2014 illustrates that Vietnam obtains the gaining trends in 14 agricultural sectors with $\beta>0$ and the losing trends in 37 agricultural sectors with $\beta<0$. The country has the most increasing comparative advantages in the sectors of 034, 231, 071, 037, and 057 . It also predicts that Vietnam might continue to obtain the stronger comparative advantage in these sectors in the future. Conversely, Vietnam has the most decreasing comparative advantages in the sectors of 222, 012, 022, 422, and 112 (Table 8). In general, Vietnam has less gaining trends than losing trends in competitiveness by both indicators.

The dynamics analysis result proves that Vietnam's agricultural export strategy and comparative advantage pattern are relatively dependent on the natural-resource-intensive and traditional agricultural products such as crop and fishery sectors over time. Though there are changes in the competitiveness rankings of the strongest competitive commodities and the convergent pattern in the agricultural competitiveness over the period 1997-2014 which may be considered as a slight improvement of the export strategy and economic growth pattern, the naturalresource-intensive and traditional products are the strongest competitive and main export agricultural sectors of the country.

\begin{tabular}{llccccc}
\hline Code & Commodity & $\boldsymbol{\beta}$ & p-value & $\mathbf{R}^{2}$ & RCA (1997) & RCA (2014) \\
\hline 246 & Wood in chips, particles & 1.240 & 0.000 & 0.88 & 4.99 & 18.41 \\
037 & Fish etc.prepd,prsvd.nes & 0.396 & 0.000 & 0.64 & 6.76 & 8.92 \\
034 & Fish,fresh,chilled,frozn & 0.323 & 0.003 & 0.44 & 2.74 & 5.22 \\
265 & Vegetable textile fibres & 0.222 & 0.066 & 0.20 & 3.97 & 3.98 \\
411 & Animal oils and fats & 0.140 & 0.000 & 0.81 & 0.01 & 1.31 \\
046 & Meal,flour of wheat,msln & 0.103 & 0.000 & 0.89 & 0.16 & 1.49 \\
062 & Sugar confectionery & 0.081 & 0.000 & 0.60 & 0.55 & 1.02 \\
261 & Silk & -0.346 & 0.000 & 0.66 & 6.59 & 0.22 \\
074 & Tea and mate & -0.393 & 0.000 & 0.77 & 11.38 & 3.60 \\
071 & Coffee,coffee substitute & -0.448 & 0.006 & 0.39 & 17.45 & 11.31 \\
231 & Natural rubber, etc. & -0.461 & 0.007 & 0.37 & 19.90 & 12.52 \\
245 & Fuel wood, wood charcoal & -0.498 & 0.063 & 0.20 & 6.53 & 1.31 \\
036 & Crustaceans,molluscs etc & -1.226 & 0.000 & 0.58 & 20.62 & 9.54 \\
042 & Rice & -2.468 & 0.000 & 0.85 & 66.33 & 14.00 \\
\hline & Gaining trend groups & $\mathbf{1 9}$ & & & & \\
\hline
\end{tabular}

Source: own calculation based on data of UN Comtrade (2017)

Table 7: The top gaining and losing trends of the RCA indicators (selected). 


\begin{tabular}{llccccc}
\hline Code & Commodity & $\boldsymbol{\beta}$ & p-value & $\mathbf{R}^{2}$ & RCA (1997) & RCA (2014) \\
\hline 034 & Fish,fresh,chilled,frozn & 0.082 & 0.000 & 0.91 & -0.03 & -0.10 \\
231 & Natural rubber,etc. & 0.069 & 0.000 & 0.78 & -0.04 & -0.21 \\
071 & Coffee,coffee substitute & 0.058 & 0.000 & 0.57 & -0.03 & -0.31 \\
037 & Fish etc.prepd,prsvd.nes & 0.047 & 0.000 & 0.85 & -0.01 & -0.02 \\
057 & Fruit,nuts excl.oil nuts & 0.040 & 0.000 & 0.89 & -0.01 & -0.09 \\
246 & Wood in chips,particles & 0.033 & 0.000 & 0.80 & -0.04 & -0.17 \\
075 & Spices & 0.023 & 0.000 & 0.63 & -0.01 & -0.04 \\
098 & Edible prod.preprtns,nes & -0.008 & 0.000 & 0.78 & -0.01 & -0.03 \\
041 & Wheat,meslin,unmilled & -0.009 & 0.000 & 0.78 & 0.04 & -0.03 \\
112 & Alcoholic beverages & -0.009 & 0.000 & 0.91 & -0.01 & -0.13 \\
422 & Fixed veg.fat,oils,other & -0.010 & 0.000 & 0.87 & -0.01 & 0.01 \\
022 & Milk and cream & -0.012 & 0.002 & 0.47 & -0.04 & -0.09 \\
012 & Other meat,meat offal & -0.014 & 0.000 & 0.84 & 0.02 & -0.15 \\
222 & Oilseed(sft.fix veg.oil) & -0.022 & 0.000 & 0.90 & -0.01 & -0.05 \\
\hline & Gaining trend groups & $\mathbf{1 4}$ & & & & \\
\hline
\end{tabular}

Source: own calculation based on data of UN Comtrade (2017)

Table 8: The top gaining and losing trends of the NRCA indicators (selected).

Testing the consistency between the $R C A$, the $R T A$, and the $N R C A$ indices

This section uses the $R C A$, the $N R C A$ indicators calculated in this paper and the $R T A$ data computed in Hoang et al. (2017) to test the consistency between the comparative advantage indices of the $R C A$, the $R T A$, and the $N R C A$. The sectorranking consistency tests for the $R C A, R T A$, and NRCA indices as cardinal, ordinal and dichotomous measures indicate the general differences and similarities of these indicators in assessing and ranking the competitiveness. The result, generally, shows in Table 9 that these indices are strongly consistent as cardinal and dichotomous measures while they are averagely consistent as ordinal measures. This means that the counting both export and import data in the RTA may not significantly impact on identifying the degrees of the agricultural competitiveness and determining whether a country obtains the competitiveness in an agricultural sector while the counting import data may relatively change the competitiveness rankings of the agricultural sectors.

As cardinal measures, the correlation coefficients of the $R C A$ and the RTA, the RCA and the NRCA, the $R T A$ and the NRCA are relative high with the average coefficient values of $0.96,0.86$, and 0.83 , respectively. This means that the $R C A$ and the $R T A$ are extremely consistent and the $R C A$ and the $N R C A$, the $R T A$ and the $N R C A$ are strongly consistent to identify and explain the degrees and structures of the agricultural competitiveness. As ordinal measures, the correlation coefficients of the $R C A$ and the RTA, the RTA and the NRCA are relatively low while the correlation coefficient of the $R C A$ and the $N R C A$ is relatively high with the mean coefficient values of $0.65,0.66$, and 0.75 , respectively. This means that the $R C A$ and the $N R C A$ are strongly consistent while the $R T A$ and the $R C A$, the $R T A$ and the $N R C A$ are weakly consistent to rank and explain the positions and structures of the agricultural competitiveness. As dichotomous measures, the $R C A$ and the $N R C A$ are perfectly consistent with the matching shares of 100 percent due to the derivation of the $N R C A$ from the neutral-point of the RCA. The consistencies between the RTA and the RCA, the RTA and the $N R C A$ are relatively strong with the same matching shares of 80 percent in the average and similar matching shares in all years. In other words, the $R C A$ and the NRCA are perfectly consistent and the RTA and the RCA, the RTA and the $N R C A$ are strongly consistent to determine whether a country obtains the competitiveness in an agricultural sector and explain the competitiveness structures. 


\begin{tabular}{|c|c|c|c|c|c|c|c|c|c|}
\hline \multirow[b]{3}{*}{ Year } & \multicolumn{3}{|c|}{ Cardinal } & \multicolumn{3}{|c|}{ Ordinal } & \multicolumn{3}{|c|}{ Dichotomous } \\
\hline & RCA & RCA & RTA & RCA & $\mathrm{RCA}$ & RTA & RCA & RCA & RTA \\
\hline & RTA & NRCA & NRCA & RTA & NRCA & NRCA & RTA & NRCA & NRCA \\
\hline 1997 & 0.98 & 0.91 & 0.90 & 0.79 & 0.75 & 0.72 & 0.75 & 1.00 & 0.75 \\
\hline 1998 & 0.96 & 0.94 & 0.91 & 0.64 & 0.65 & 0.63 & 0.84 & 1.00 & 0.75 \\
\hline 1999 & 0.97 & 0.91 & 0.90 & 0.64 & 0.71 & 0.61 & 0.77 & 1.00 & 0.77 \\
\hline 2000 & 0.98 & 0.78 & 0.79 & 0.64 & 0.79 & 0.70 & 0.77 & 1.00 & 0.77 \\
\hline 2001 & 0.96 & 0.85 & 0.84 & 0.70 & 0.81 & 0.63 & 0.75 & 1.00 & 0.75 \\
\hline 2002 & 0.98 & 0.84 & 0.84 & 0.63 & 0.82 & 0.63 & 0.74 & 1.00 & 0.74 \\
\hline 2003 & 0.97 & 0.87 & 0.87 & 0.60 & 0.80 & 0.60 & 0.74 & 1.00 & 0.74 \\
\hline 2004 & 0.94 & 0.88 & 0.84 & 0.62 & 0.74 & 0.63 & 0.80 & 1.00 & 0.80 \\
\hline 2005 & 0.94 & 0.89 & 0.84 & 0.61 & 0.79 & 0.61 & 0.77 & 1.00 & 0.77 \\
\hline 2006 & 0.96 & 0.88 & 0.84 & 0.57 & 0.79 & 0.62 & 0.75 & 1.00 & 0.75 \\
\hline 2007 & 0.97 & 0.89 & 0.86 & 0.63 & 0.78 & 0.66 & 0.82 & 1.00 & 0.82 \\
\hline 2008 & 0.96 & 0.91 & 0.88 & 0.67 & 0.75 & 0.68 & 0.89 & 1.00 & 0.89 \\
\hline 2009 & 0.96 & 0.87 & 0.84 & 0.65 & 0.73 & 0.70 & 0.84 & 1.00 & 0.84 \\
\hline 2010 & 0.93 & 0.88 & 0.82 & 0.65 & 0.75 & 0.71 & 0.87 & 1.00 & 0.87 \\
\hline 2011 & 0.95 & 0.81 & 0.77 & 0.62 & 0.78 & 0.69 & 0.82 & 1.00 & 0.82 \\
\hline 2012 & 0.94 & 0.81 & 0.76 & 0.63 & 0.72 & 0.68 & 0.82 & 1.00 & 0.82 \\
\hline 2013 & 0.92 & 0.79 & 0.72 & 0.63 & 0.72 & 0.70 & 0.87 & 1.00 & 0.87 \\
\hline 2014 & 0.94 & 0.79 & 0.73 & 0.68 & 0.68 & 0.71 & 0.84 & 1.00 & 0.84 \\
\hline Average & 0.96 & 0.86 & 0.83 & 0.65 & 0.75 & 0.66 & 0.80 & 1.00 & 0.80 \\
\hline
\end{tabular}

Source: own calculation based on data of UN Comtrade (2017)

Table 9: The consistency between the RCA, the NRCA, and the RTA indices.

\section{Conclusion}

The results show that, in 2014, Vietnam obtains the strongest $R C A s$ in $246,075,042,231,071$, 036 , and 037 with the RCA values of $18.41,17.57$, $14.00,12.52,11.31,9.54$, and 8.92 , respectively, whilst it achieves the strongest NRCAs in 071, 042, 036, 034, 037, 057, and 231 with the $N R C A$ values of $1.76,1.48,1.45,1.18,0.96,0.94$, and 0.83 , respectively. Vietnam, by the $R C A$, achieves the competitiveness in 19 agricultural sectors with 4 strong competitive sectors, 4 medium competitive sectors, and 11 weak competitive sectors. The country, by the $N R C A$, also gains the competitiveness in 19 agricultural sectors with 9 strong competitive sectors, 2 medium competitive sectors, and 8 weak competitive sectors. In overall, by both indices, Vietnam obtains strong comparative advantages in the crop sectors such as spices, rice, coffee, tea, fruit and nut, and vegetables; and the fishery sectors such as crustaceans and fish whilst the country has weak comparative advantages in the livestock sectors such as live animal, meat, and egg and birds; and the processed food sectors such as chocolate, cheese, butter, and other processed meat and foods. In other words, the country has agricultural export strategy and competitiveness pattern based on the natural-resource-intensive and traditional agricultural sectors.

OLS estimation for the RSCA indicators shows that Vietnam has the convergent pattern in the agricultural competitiveness. In other words, the country loses the competitiveness in the initial strong competitive sectors whilst it gains the competitiveness in the initial weak competitive sectors. However, OLS estimation for the $N R C A$ values results in a divergent pattern in agricultural competitiveness. In other words, Vietnam gains the increasing competitiveness in the initial strong competitive sectors whilst it loses the competitiveness in the initial weak competitive sectors. Markov matrices for both the $R C A$ and the NRCA, generally, indicate that the comparative disadvantage sectors and strong comparative advantage sectors are the most stable to remain in their initial groups, especially the strong competitive sectors by the NRCA perfectly stay in its class. The trend analysis reveals that Vietnam obtains the gaining trends in 19 agricultural sectors by the $R C A$ and 14 agricultural sectors by the NRCA. The country, however, has the losing trends in 23 agricultural sectors by the $R C A$ and in 37 agricultural sectors by the $N R C A$. 
The dynamics analysis also proves that, in overall, Vietnam's export strategy and comparative advantage pattern are relatively dependent on the natural-resource-intensive and traditional agricultural sectors such as crop and fishery sectors over time. Though there are changes in the competitiveness rankings of the strongest competitive commodities and the convergent pattern in the agricultural competitiveness over the period 1997-2014 which may be considered as a small improvement of the export and economic growth pattern, the natural-resourceintensive and traditional products are the strongest competitive and main export agricultural sectors of the Vietnam. The natural-resource-intensive export strategy is important in the initial period of economic development and globalization but not appropriate and effective in the medium and long terms. The country, therefore, should re-structure and enhance the effective agricultural production and competitiveness patterns with focusing on the high value added, technology- and capitalintensive, and market-oriented products based

Corresponding author:

Viet Van Hoang

University of Economics Ho Chi Minh City

59C Nguyen Dinh Chieu Street, Ward 6, District 3, Ho Chi Minh City, Vietnam

Phone: +84903688 447,E-mail: viet.hoang@ueh.edu.vn

\section{References}

[1] Abidin, M. Z. and Loke, W. H. (2008) "Revealed comparative advantage of Malaysian exports: The case for changing export composition", Asian Economic Papers, Vol. 7, No. 3, pp. 130-147. ISSN 1535-3516. DOI 10.1162/asep.2008.7.3.130.

[2] Balassa, B. (1965) "Trade liberalisation and "revealed" comparative advantage", The Manchester School, Vol. 33, No. 2, pp. 99-123. DOI 10.1111/j.1467-9957.1965.tb00050.x.

[3] Brasili, A., Epifani, P. and Helg, R. (2000) "On the Dynamics of Trade Patterns", De Economist, Vol. 148, No.2, pp. 233-257. ISSN 0013-063X. DOI 10.1023/A:1004065229330.

[4] Cai, J. and Leung, P. S. (2008) "Towards a more general measure of revealed comparative advantage variation", Applied Economics Letters, Vol. 15, No. 9, pp. 723-726. ISSN 1350-4851.

[5] Cantwell, J. (1989) "Technological innovation and multinational corporations", Cambridge: B. Blackwell, 239 p. ISBN 0631138471.

[6] Ceglowski, J. (2017) "Assessing Export Competitiveness through the Lens of Value Added", The World Economy, Vol. 40, No. 2, pp. 275-296. ISSN 1467-9701. DOI 10.1111/twec.12362.

[7] Dalum, B., Laursen, K. and Villumsen, G. (1998) "Structural change in OECD export specialisation patterns: de-specialisation and stickiness", International Review of Applied Economics, Vol. 12, No. 3, pp. 423-443. ISSN 0269-2171/1465-3486. DOI 10.1080/02692179800000017.

[8] Deb, K. and Hauk, W. R. (2017) "RCA indices, multinational production and the Ricardian trade model", International Economics and Economic Policy, Vol. 14, No.1, pp. 1-25. ISSN 1612-4804. DOI 10.1007/s10368-015-0317-z. 
[9] Esquivias, M. A. (2017) "The Change of Comparative Advantage of Agricultural Activities in East Java within the Context of ASEAN Economic Integration", AGRIS on-line Papers in Economics and Informatics, Vol. 9, No. 1, pp. 33 - 47. ISSN 1804-1930. DOI 10.7160/aol.2017.090103.

[10] Ferto, I. and Hubbard, J. L. (2003) "Revealed comparative advantage and competitiveness in Hungarian agri-food sectors", The World Economy, Vol. 26, pp. 247-259. ISSN 1467-9701. DOI 10.1111/1467-9701.00520.

[11] Ferto, I. and Soos, K. A. (2008) "Trade specialization in the European Union and in post-communist European countries", Eastern European Economics, Vol. 46, No. 3, pp. 5-28. ISSN 0012-8775.

[12] Gorton, M., Davidova, S. and Ratinger, T. (2000) "The competitiveness of agriculture in Bulgaria and the Czech Republic vs the European Union", Comparative Economic Studies, Vol. 42, No. 1, pp. 59-86. ISSN 0888-7233. DOI 10.1057/ces.2000.2.

[13] Hart, P. E. (1976) "The dynamics of earning, 1963-1973", Economics Journal, Vol. 86, No. 343, pp. 551-565. DOI 10.2307/2230799.

[14] Hart, P. E. and Prais, S. J. (1956) "The analysis of business concentration: a statistical approach", Journal of the Royal Statistical Society. Series A (General), Vol. 119, No. 2, pp. 150-191. DOI $10.2307 / 2342882$.

[15] Hinloopen, J. and Marrewijk, C. V. (2001) „On the empirical distribution of the Balassa index“, Weltwirtschaftliches Archiv, Vol. 137, No.1, pp. 1-35. ISSN 1610-2878/1610-2886. DOI 10.1007/BF02707598.

[16] Hoang, V.V ., Tran, K. T. and Tu, B.V . (2017) "Assessing the Agricultural Competitive Advantage by the RTA index: A Case Study in Vietnam", AGRIS on-line Papers in Economics and Informatics, Vol. 9, No. 3, pp. 15 - 26. ISSN 1804-1930. DOI 10.7160/aol.2017.090302.

[17] Hoen, A. R. and Oosterhaven, J. (2006) „On the measurement of comparative advantage“, The Annals of Regional Science, Vol. 40, No. 3, pp. 677-691.

[18] Kreinin, M. E. and Plummer, M. G. (1994) „Structural change and regional integration in East Asia“, International Economic Journal, Vol. 8, No. 2, pp. 1-12.

[19] Krugman, P. R. (1994) “Competitiveness-A dangerous obsession”, Foreign Affairs, Vol. 73, No. 2, pp. 28-44. ISSN 00157120. DOI 10.2307/20045917.

[20] Kuldilok, K. S., Dawson, P. J. and Lingard, J. (2013) „The export competitiveness of the tuna industry in Thailand“, British Food Journal, Vol. 115, No. 3, pp. 328-341. ISSN 0007-070X. DOI 10.1108/00070701311314174.

[21] Kunimoto, K. (1977) „Typology of trade intensity indices“, Hitotsubashi Journal of Economics, Vol. 17, No. 2, pp. 15-32. ISSN 0007-070X. DOI 10.15057/7981.

[22] Liesner, H. H. (1958) "The European common market and British industry", The Economic Journal, Vol. 68, No. 270, pp. 302-316. ISSN 1468-0297. DOI 10.2307/2227597.

[23] Lucas, R. (1988) "On the Mechanics of Economic Development", Journal of Monetary Economics, Vol. 22, No. 1, pp. 3-22. ISSN 0304-3932. DOI 10.1016/0304-3932(88)90168-7.

[24] Martin, R. L. (2003) "A study on the factors of regional competitiveness", A draft final report for The European Commission Directorate-General Regional Policy, Cambridge: University of Cambridge.

[25] Nath, H. K., Liu, L. and Tochkov, K. (2015) "Comparative advantages in US bilateral services trade with China and India", Journal of Asian Economics, Vol. 38, pp. 79-92. ISSN 1049-0078. DOI 10.1016/j.asieco.2015.04.002.

[26] Proudman, J. and Redding, S. (2000) "Evolving patterns of international trade", Review of international economics, Vol. 8, No. 3, pp. 373-396. ISSN 1467-9396. DOI 10.1111/1467-9396.00229. 
[27] Sarker, R. and Ratnasena, S. (2014) "Revealed Comparative Advantage and Half-a-Century Competitiveness of Canadian Agriculture: A Case Study of Wheat, Beef, and Pork Sectors", Canadian Journal of Agricultural Economics, Vol. 62, No. 4, pp. 519-544. ISSN 1744-7976. DOI 10.1111/cjag.12057.

[28] Seleka, T. B. and Kebakile, P. G. (2017) "Export Competitiveness of Botswana's Beef Industry", The International Trade Journal, Vol. 31, No.1, pp. 76-101. ISSN 0885-3908. DOI 10.1080/08853908.2016.1199982.

[29] Shorrocks, A. F. (1978) "The measurement of mobility", Econometrica: Journal of the Econometric Society, pp. 1013-1024. ISSN 00129682. DOI 10.2307/1911433.

[30] United Nations Comtrade (2017) [Online]. Available: http://comtrade.un.org/data/ [Accessed: 10 May, 2017].

[31] Vollrath, T. (1991) "A theoretical evaluation of alternative trade intensity measures of revealed comparative advantage", Review of World Economics, Vol. 127, No. 2, pp. 265-280. ISSN 1610-2878/1610-2886. DOI 10.1007/BF02707986.

[32] Young, A. (1991) "Learning-by-Doing and Dynamic Effects of International Trade", Quarterly Journal of Economics, Vol. 106, No. 2, pp. 396-406. ISSN 0033-5533. DOI 10.2307/2937942.

[33] Yu, R., Cai, J. and Leung, P. S. (2009) "The normalized revealed comparative advantage index", The Annals of Regional Science, Vol. 43, pp. 267-282. ISSN 0570-1864. DOI 10.1007/s00168-008-0213-3. 